\begin{tabular}{|l|l|}
\hline & \\
\hline
\end{tabular}

RESENHA

\title{
Por uma história pública
}

For a public history

Por una historia pública

Lucas Carvalho Soares de Aguiar Pereira ${ }^{1}$

orcid.org/0000-0001-9140-2002

lucas.pereira@ifmg.edu.br
Resumo: Resenha do livro MAUAD, Ana Maria; SANTIAGO, Ricardo; BORGES, Viviane Trindade. Que história pública queremos?: What Public History do we want? São Paulo: Letra e Voz, 2018.
Recebido em: 25/02/2021 Aprovado em: 30/03/2021 Publicado em: 31/08/2021
Artigo está licenciado sob forma de uma licença Creative Commons Atribuição 4.0 Internacional.
Os estudos históricos têm enfrentado, nas últimas décadas, desafios relacionados à sua legitimidade, credibilidade e autorização social em diferentes niveis. O maior deles é o caso do crescente negacionismo que atravessa o combate pela história de modo cada vez mais frequente. Nesse cenário, as atividades de história pública vem sendo conduzidas no sentido de desestabilizar essas críticas, uma vez que têm como característica a participação do público nos debates que envolvem a construção das próprias pesquisas e/ou do seu produto final.

Nesta última década, no Brasil, assistimos uma crescente participação de historiadoras e historiadores no cenário público, seja como agentes de intervenção em momentos especificos, seja como autores que abrem e partilham suas epistemologias, seus problemas e posicionamentos com o público. Diversos cursos, encontros e seminários ocorreram a partir desse encontro entre diferentes grupos sociais e uma comunidade de historiadores. Estas última, em suas práticas e experiências posteriores, se viu diante do desafio de construir uma rede de apoio, espaços de reflexão, debates e elaboração de projetos coletivos, de organizar, enfim, práticas e discursos que envolvem o caráter público da historiografia que praticavam e que queriam praticar, organizando a Rede Brasileira de História Pública. 
No meio dessa vasta produção se destaca o livro "Que história pública queremos?", publicado em 2018 pela editora Letra e Voz, organizado por Ana Maria Mauad (UFF), Ricardo Santhiago (UNIFESP) e Viviane Trindade Borges (UDESC)². A editora Letra e Voz tem sido um lócus de debate, reflexão e divulgação de pesquisas recentes na área de História Oral e de História Pública, contribuindo para qualificar o debate historiográfico nacional. Essa edição, em especial, tem um caráter ímpar: trata-se de um conjunto de 20 capítulos curtos, escritos por historiadores que buscaram responder perguntas de suas áreas de atuação formuladas pelos organizadores. As questões elaboradas tentaram estabelecer uma interrogação sobre as possibilidades de relação entre a história pública e os temas de pequisa dos respectivos autores, convidando à reflexão sobre "a dimensão pública do conhecimento histórico" que produzimos (p. 11). Assim, cada capítulo aborda os problemas propostos em poucas páginas. Além disso, os textos foram traduzidos para o inglês, o que contribui ainda mais para a internacionalização da discussão que tem sido conduzida no Brasil.

Os três primeiros capítulos possuem em comum a questão da atuação dos profissionais da história, bacharéis ou licenciados, diante dos desafios que se apresentam para o ensino de história e para a atuação profissional conectada com a história pública. Benito Schmidt, respondendo à questão "Qual a relação entre a história pública e a profissionalização do historiador?", estabelece que o cruzamento entre o crescimento da história pública no Brasil e o processo de regulamentação da profissão de historiador, que se deu pelo debate público em torno da necessidade de garantias de profissionais da história, que tinham pouco espaço de revindicações trabalhistas ou legais, em um país com mercado de trabalho altamente regulamentado ${ }^{3}$ Já Rodrigo de Almeida Ferreira reflete sobre a "relação entre a história pública e o ensino de História", defendendo a necessidade de professores de história e de historiadores ocuparem espaços públicos no sentido de fomentar diálogos profícuos e uma "produção compartilhada" (p. 38). Um dos exemplos mobilizados por Rodrigo Ferreira é o crescente interesse de professores da rede básica de educação pelo tema da História Pública e pelo Mestrado Profissional em Ensino de História (ProfHistória). A aposta do autor é que a reflexão sobre esse problema qualifica nossas práticas e metodologias (p. 38). A historiadora Marieta de Moraes Ferreira aborda justamente as "afinidades" entre esse mestrado e a história pública, partindo da definição de que a história pública "é aquela que circula em diversos espaços sociais através de um grande número de formas e suportes" (p.49). No artigo, a autora traça um panorama da história da formação de professores no Brasil no que diz respeito às diretrizes federais. Se o mestrado profissional, nas normativas brasileiras, tem como função a articulação entre conhecimento e sua aplicação em um campo profissional específico, podemos pensar o ProfHistória como uma espécie de espaço de tradução do "conhecimento acadêmico da área para um público mais amplo não especializado" (p. 58).

Ao ser indagado se "Todo patrimônio é uma forma de história pública?", José Newton Meneses afirma categoricamente que sim. "É história" por estar conectado ao registro temporal da construção da memória que gera o "sentido patrimonial" e "é pública" pois se coloca como um bem de e para "a fruição" e "o bem de todos" (p. 69). O autor chama a atenção para os "processos interpretativos" - marcadamente o da construção da memória social - e para a "experiência partilhada" que são inerentes aos debates públicos em torno dos patrimônios culturais (p.70-72). Esses debates ganharam dimensões "cada vez mais democra-

\footnotetext{
2 Ana Maria Mauad é pesquisadora do LABHOI/UFF, laboratório do qual já foi coordenadora, e atua com temas da história oral, história visual e história da memória. Ricardo Santhiago é coordenador do Centro de Memória da Zona Leste, atuando em projetos de história pública e história oral. E Viviane Trindade Borges coordena o Laboratório de Patrimônio Cultura, e trabalha com temas ligados à história instituições de confinamento, como prisões e manicômios.

3 O texto saiu antes da regulamentação e, por isso, foi escrito em tom de esperança. A regulamentação foi assinada, finalmente, em 2020 após duas décadas de discussão pública e uma atuação intensa da associação nacional de historiadores e foi vista como uma vitória simbólica diante dos avanços autoritários que assolam o país. Recentemente, os primeiros registros profissionais já foram expedidos.
} 
tizadas" (p. 69) e contribuem para o ensino da história em uma dimensão não escolar. Assim, para Meneses, "todo patrimônio é (...) história, posta na arena pública para a compreensão dos públicos" (p. 75). No texto seguinte, de Viviane Trindade Borges, somos convidados a refletir sobre a preservação de estruturas arquitetônicas de confinamento ou de privação de liberdade, entendidos como "patrimônio difícil", pois são estruturas arquitetônicas que "incomodam" e perturbam o presente (p. 88). O texto apresenta o debate sobre os "novos usos" desses espaços, como a ocupação de um hospital psiquiátrico em Porto Alegre por uma companhia de teatro. Viviane Borges, porém, problematiza esse processo, chamando a atenção para o "vazio" que existe em relação à preservação da "memória dos sujeitos" que foram internados ou que viveram nesses espaços (p. 92). A autora nos provoca a refletir sobre essa questão, argumentando que "muitas vezes a valorização do vivido torna-se parte fundamental para que, de fato, patrimônio e memória atuem como vetores nos processos de reparação" (p. 92).

No capítulo seguinte, somos convidados a refletir sobre os ensinamentos da história oral à história pública. "O que a história oral ensina à história pública?" é a questão motivadora do texto de Juniele Rabêlo de Almeida. A autora propõe a retomada do "princípio público do espaço comum" para que possamos dar um passo para além do "fetiche do produto como resultado de grandes projetos" (p. 110). Apesar de frisar as origens distintas da historia oral e da história pública, Juniele Almeida reconhece a "convergência gradual de ambas" (p. 104) e nos convida a focar nos aprendizado mútuo desses dois movimentos: a relação com as comunidades, a sensibilidade para o diálogo, as possibilidades de parcerias, o estabelecimento de agenda de debates públicos, entre outros. Trata-se de repensar o caráter coletivo e público da construção dos problemas norteadores das pesquisas em história pública ou em história oral.

Ana Maria Mauad considera a fotografia pública como uma noção e uma prática que está inserida no espaço público e que, nesse sentido, produz um imaginário social e uma memória social. Para a historiadora, a fotografia pública faz uma leitura pública da história, em especial no século XX. inserindo-se nos processos de construção de memória social. As razões para tanto residem no tratamento dado por essa prática fotográfica ao espaço público e por ter nesse local "o seu lugar de referência política" (p.129). Paulo Knauss, em "Quais os desafios dos museus em face da história pública?", elenca as funções históricas do museu, passando de sua missão pedagógica para a nação até o movimento de abertura museológica para a diversidade cultural, problema que se coloca no último quartel do século XX. A abertura do museu para o público se dá, então, a partir de uma concepção de museu como uma "instituição a serviço da sociedade", que tem um papel na "transformação das estruturas" sociais (p. 144). Os dilemas, segundo o autor, são "próximos" daqueles enfrentados pela própria historiografia acadêmica: conquistar novas audiências, consolidar parcerias com público para leitura colaborativa do acervo, consolidar uma "autoridade compartilhada". O texto finaliza apontando, rapidamente, o desafio de construção de espaço de liberdade e dignidade humana posto pelos museus que lidam com os traumas coletivos dos últimos séculos - questão da tradição kantiana humanista que fica em aberto. Mas este problema foi explorado pelos textos de José Meneses e Viviane Borges, mencionados anteriormente. Em uma segunda edição, caberia, talvez, um deslocamento desse artigo inserindo-o em lugar mais próximo desses dois textos, dando mais organicidade à leitura.

Miriam Hermeto mobiliza a noção de "autoridade compartilhada" ao responder positivamente à questão "Podem os palcos ser lugar de história pública?". A produção, reflexão e circulação da história do Brasil pelos palcos do teatro é o tema do capítulo, que analisa a produção teatral de Chico Buarque (p. 153). A obra do artista, segundo a autora, tem uma interlocução tanto com o passado brasileiro, quanto com o presente em que ela foi produzida, construindo, assim, "representações 
da história do Brasil" e dialogando com públicos mais amplos. A tese da autora é que Chico Buarque realizou um "exercício daquilo que hoje chamamos de história pública" (p. 160). Em "Onde fica a autoridade do historiador no universo digital?", Bruno Leal retraça os caminhos da invenção da autoridade científica historiográfica e como essa "autoridade" tem sido "desafiada" em diferentes contextos: pelo mercado editorial que privilegiou autores jornalistas, pelo negacionismo do holocausto e, agora, pela tendência pulverizadora dos saberes a partir do advento da internet (p. 170). O autor afirma, no entanto, que essa autoridade "não desapareceu (...)" mas "tem sido eclipsada por uma multiplicidade de discursos" que antes não tinham destaque (p. 171) e que passaram a disputar politicamente a interpretação do passado, servindo de base cultural para movimentos de extrema direita brasileira. A aposta, então, é que a historiografia precisa "atuar" no espaço digital, construindo uma conexão com o público e com o tempo presente (p. 174).

O texto de Sônia Meneses traça os caminhos históricos do processo de concentração midiática no Brasil, com destaque analítico para o grupo Globo, que detém "as audiências somadas do $2^{\circ}$, $3^{\circ} 4^{\circ}$ e $5^{\circ}$ maiores grupos brasileiros" de mídias (p. 183). A tese da autora é que a mídia é capaz de produzir conhecimento e acontecimento, dividindo sua atuação em dois momentos: "a 'escritura' do evento na cena pública" e a "inscrição" do evento "no tempo" (p.183-184). No primeiro momento, a história pública funda sentido e no segundo produz "fatos de memória" (p. 184-185). Na visão da autora, somente com a democratização das mídias no Brasil será possivel produzir uma história pública nas diferentes mídias que seja comprometida com os elementos fundantes da prática historiadora como: ética, pluralidade, crítica das fontes (p. 187).

Nos três capitulos seguintes, somos levados a pensar sobre temas sensiveis frente à história pública. "Qual o papel da história pública frente ao revisionismo histórico?" de Carolina Bauer, explora o problema do revisionismo da história da última ditadura militar brasileira. Para a autora, a famosa "batalha das memórias" nunca foi ganha, de fato, pois as representações que reabilitaram a ditadura seguiram em construção, circulação e legitimação em uma "comunidade de memórias" (p.198). Dialogando implicitamente com o texto de Bruno Leal, Bauer nos indica a necessidade de não nos silenciarmos diante do negacionismo, do "revisionismo apologético" da ditadura e da tortura. Para Bauer, a história pública tem o papel de interrogar esse passado e essas abordagens no sentido de "estimular a reflexão" e romper com o lugar de emissão de opinião (p. 203).

Também no texto "É possivel uma história pública dos temas sensiveis no Brasil?", de Samantha Quadrat, a história pública é provocada a tomar lugar no debate sobre os espaços em onde tenham ocorrido experiências sociais dolorosas, traumáticas e sensiveis, como os sitios da escravidão e da tortura na ditadura militar. Esses espaços, transformados em lugares de memória, são entendidos como locais em que podemos "construir coletivamente o conhecimento do passado através de novas subjetividades e de múltiplas e diferentes narrativas sobre a experiência do horror" (p. 220). O texto "Que diferença faz a perspectiva da história pública nos estudos sobre a escravidão?", de Hebe Mattos, Keila Grinberg e Martha Abreu, parte do debate público sobre o racismo e a escravidão no Brasil e a crescente produção cultural sobre os temas. As tensões entre diferentes conhecimentos levam à indagação sobre como "construir uma visão historicamente correta da escravidão que seja, ao mesmo tempo, sensivel e complexa" (p. 232). As autoras retomam os belos caminhos trilhados pelo projeto "Passados Presentes: memória da escravidão no Brasil", construido e desenvolvido em parceria. Parceria intelectual entre historiadoras, historiadores, profissionais do audiovisual, da comunicação e do turismo e, finalmente, comunidades envolvidas, forjando, enfim, uma obra coletiva de história pública brasileira. As autoras nos lembram que, apesar de não termos controle das formas como o público vai ler e interpretar o passado, a história pública, entendida como uma ação política, precisa se posicionar. Nesse sentido, 
elas enfatizam: "não cabem leituras nostálgicas ou indiferentes do passado" (p. 236).

Nos dois capítulos seguintes, somos convidados a refletir sobre os comprometimentos politicos da história pública. No caso da diversidade LGBT, James Green elenca a importância de se constituir possibilidades de acesso a acervos documentais sobre a história e memória do ativismo LGBT no Brasil, destacando a ação do jornal "Lampião da Esquina" e do "Somos: Grupo de Afirmação Homossexual". O papel da história pública, nesse caso, é o compromisso com a "coleta e disseminação em acesso aberto desse material" (p. 253). Essa ação política da história pública seria, na visão do autor, um compromisso com a consolidação de "uma democracia radical que respeite a diversidade e que a estimule a florescer" (p.254). O compromisso com a democracia é a tônica do texto de Hebe Mattos, que reflete sobre o movimento "Historiadores pela Democracia", organizado a partir do golpe parlamentar que impediu a presidenta Dilma Rousseff, retirando-a da presidência. A autora entende que a "agenda conservadora" entrou na pauta governista "sem o referendo das urnas" (p.263). O compromisso das/os historiadores diante desse cenário seria, portanto, "escrever de forma que os não especialistas pudessem entender o sentido mais profundo da disciplina" (p. 264), como entendia Marc Bloch. Hebe Matos argumenta que somente com novas eleições gerais teremos alguma "esperança" diante da "crise de legitimidade política" da década de 2010, mas cabe ressaltar que essa agenda antidemocrática ocupou lugar nas duas últimas eleições (de 2018, no âmbito federal e estadual e de 2020, no âmbito municipal) e essa esperança precisa ser informada por outros elementos de participação política para além das urnas.

Dos quatro último textos, dois colocam questões metodológicas importantes e os outros dois se questionam sobre o fazer história pública na América Latina e no Brasil. Em "A história pública serve para a teoria da história, e vice-versa?", Rogério Rosa Rodrigues lança mão da proposição de Droysen, para quem o método histórico tem como essência o fato de que a compreensão se dá durante a própria execução da pesquisa (p.279). Haveria uma convergência metodológica, portanto, entre a historia acadêmica e a história pública, uma vez que "a compreensão" se dá "no percurso das experiências" (dialogando, assim, com a conclusão do texto de Rodrigo Almeida, no capítulo 3 deste livro). No entanto, o autor ressalva a importância de conjugar esse processo "com o esforço de teorização" (p. 280). Rodrigues propõe, então, que os currículos de formação de profissionais da história coloquem "a reflexão a serviço de um saber plural (...) e aberto às demandas e problemas do tempo presente" (p. 283). Já em "História pública, por que não?", Richard Cándida Smith apresenta uma análise do papel fundamental da discordância e do conflito na construção da história pública. Papel, aliás, que é evitado, segundo o autor, por historiadores públicos que atuam em museus e em institutos públicos ou privados nos Estados Unidos. O texto ressalta a constante dificuldade desses projetos de história pública de superar a noção de "lições de boa cidadania" e sua "antipatia pelo conflito e pela discordância". A divisão entre história acadêmica e pública e a ficção que elege a primeira como mais rigorosa é um ponto negativo. Mas Smith argumenta que essa divisão pode ser útil para criar "espaços de análise da discordância e do conflito que é quase sempre desconfortável para a maioria dos governos" ( $p$. 299). Penso que essa análise da credibilidade da historiografia acadêmica certamente apresentará dificuldades de ser verificada ou sustentada no Brasil, tendo em vista o descrédito e os ataques que professores de historia e historiadores vêm recebendo na última década.

Finalmente, Marta Gouveia de Oliveira Rovai argumenta pela necessidade de descolonizar a história em um contexto de permanências de processos de dominação social e cultural advindos da colonização, como as "concepções escravistas, estigmatizantes, discriminatórias [e] autoritárias" (p. 308). A história pública tem o papel social de constituição de acervos e de espaços que permitam o debate, seleção, divulgação, 
preservação de artefatos e de histórias de vida, em defesa da "dignidade humana" e contra o esquecimento produzido por uma história colonizada "que naturaliza a violência, o preconceito e a exclusão social e política na América Latina" (p. 314) Essas são as razões fundamentais para se "fomentar uma história pública latino-americana", questão inicial do texto de Rovai. Já Ricardo Santhiago responde negativamente à questão: "Pode-se falar de uma história pública brasileira?", tendo em vista o dinamismo, o teor "ecumênico" das pesquisas no país e o caráter internacional da história pública. Mas o autor defende que podemos falar de "alguma história pública brasileira". Essa prática no Brasil teria se dado, desde a década de 1970, a partir da aproximação da historiografia com o "público", intermediada pela história oral (p. 329). A história pública, essa atitude historiadora, como argumenta Ana Maria Mauad, é entendida por Santhiago como uma prática que se importa com a "escuta", o "reconhecimento", as "trocas verdadeiras" (p. 329). Essas três ações, constitutivas também da própria história oral, formaram a base de um "diálogo polifônico" que a história pública promove e permitiram uma "virada pública" da história (p. 330).

Uma tônica que percorre todo o livro é a defesa da necessidade de romper com as fronteiras que permitem o isolamento da historiografia acadêmica, partindo de uma postura de trabalho que se coloque disposta a construir saberes históricos plurais, democráticos, abertos. A publicação é um verdadeiro manifesto para esse processo, um convite à reflexão e a ações coletivas de história pública. Algumas informações ou detalhes dos temas ficaram ausentes dos textos, algo justificado pela proposta da obra. Além disso, a diversidade de temas e metodologias apresentadas pelo livro explicita o caráter plural da produção acadêmica de história pública no Brasil e reforça o lugar do dissenso nessa produção. Apesar de observarmos muitas concordâncias, as divergências em relação ao modo de desenvolver seus problemas e aos pressupostos teórico-metodológicos contribuem para a riqueza dessa publicação. Assim, o livro faz um convite para que historiadoras e historiadores brasileiros voltem sua atenção para as dimensões públicas do conhecimento histórico e para as implicações políticas e sociais do oficio, apresentando diferentes reflexões sobre as experiências de história pública no país. A publicação contribui, assim, para os combates por uma história pública, plural e diversa.

Ao final, a coletânea ainda traz um texto de uma página, de Gilberto Tomé, explicando as origens da belissima imagem da capa, pertencente ao acervo do "Santa Marina Atlético Clube" do bairro Água Branca em de São Paulo. Essa documentação é a base de um projeto de história pública que faz intervenções urbanas e traça reflexões sobre a memória da Rua do Ó, que liga a Freguesia do Ó ao bairro Água Branca desde o século XVII. A imagem, aliás, é muito provocativa e apresenta "operários músicos" encarando o futuro da história, indagando ao leitor, enfim, "Que história pública queremos construir?". Alguns caminhos possiveis foram apontados pelos vinte artigos que compõem este livro.

Lucas Carvalho Soares de Aguiar Pereira

Doutor em História Social pela Universidade Federal do Rio de Janeiro, (PPGHIS/UFRJ), professor do Instituto Federal de Minas Gerais, (IFMG), em Betim, MG, Brasil.

\section{Endereço para correspondência}

Lucas Pereira

IFMG Campus Betim

R. Itaguaçu, 595 ,

São Caetano, 32677-562

Betim, MG, Brasil. 